\title{
Optimization of steel casting feeding system based on BP neural network and genetic algorithm
}

\author{
Xue-dan Gong ${ }^{1,2}$, *Dun-ming Liao ${ }^{1}$, Tao Chen ${ }^{1}$, Jian-xin Zhou ${ }^{1}$, and Ya-jun Yin ${ }^{1}$ \\ 1. State Key Laboratory of Materials Processing and Die \& Mould Technology, Huazhong University of Science and Technology, Wuhan 430074, \\ China; \\ 2. School of Mechanical Engineering, Hubei University of Technology, Wuhan 430068, China
}

\begin{abstract}
The trial-and-error method is widely used for the current optimization of the steel casting feeding system, which is highly random, subjective and thus inefficient. In the present work, both the theoretical and the experimental research on the modeling and optimization methods of the process are studied. An approximate alternative model is established based on the Back Propagation (BP) neural network and experimental design. The process parameters of the feeding system are taken as the input, the volumes of shrinkage cavities and porosities calculated by simulation are simultaneously taken as the output. Thus, a mathematical model is established by the BP neural network to combine the input variables with the output response. Then, this model is optimized by the nonlinear optimization function of the genetic algorithm. Finally, a feeding system optimization of a steel traveling wheel is conducted. No shrinkage cavities and porosities are induced through the optimization. Compared to the initial design scheme, the process yield is increased by $4.1 \%$ and the volume of the riser is decreased by $5.48 \times 10^{6} \mathrm{~mm}^{3}$.
\end{abstract}

Key words: steel casting; numerical simulation; process parameters optimization; BP neural network

CLC numbers: TG142/TP391.9 Document code: A Article ID: 1672-6421(2016 03-182-09

A teel castings output accounts for about $13 \%$ of the total castings output due to outstanding performance

${ }^{[1]}$. Risers, chills, pads et al. are usually adopted to avoid shrinkage cavities and porosities in the casting process. These methods achieve consecutive solidification and improve the quality of steel castings ${ }^{[2]}$. Excessively large risers lead to material waste and unnecessary energy consumption. Thus, on the premise that no shrinkage cavities and porosities are induced, the decrease of the riser volume has a significant effect on reducing cost and energy consumption ${ }^{[3]}$.

Currently, the design of the steel castings process ${ }^{[4]}$ is a cyclic procedure of passive simulation and calculation. Numerical simulation is nothing but an analytical tool to verify the given design scheme, and it cannot modify the process direction. The optimized process design scheme cannot be determined automatically.

\section{* Dun-ming Liao}

Male, born in 1973, Professor, Ph. D., doctoral supervisor. His research mainly focuses on digital studies of the casting process. His academic research has led to the publication of more than 45 papers.

E-mail: liaodunming@hust.edu.cn

Received: 2016-01-11;

Accepted: 2016-04-28
Therefore, the numerical method should be combined with optimization technology to obtain the best design scheme and flawless products ${ }^{[5]}$.

Many factors of the casting process can cause shrinkage cavity and porosity defects. Besides, it is difficult to evaluate these factors with a uniform mathematical model. Hence, it is an essential issue to build an optimization model for the feeding system. Previous researchers took the cubic-equation ${ }^{[6]}$ or four-equation method as optimization models for the riser design. These methods, which are derived from the modulus method, only evaluated the influence of casting local modulus on the feeding system. None of the following process parameters are considered: pouring temperature, hot spot shape, casting structure, pouring position, and pouring time. It should be noted that these parameters greatly affect the formation of shrinkage cavities and porosities. In this study, an approximate alternative model is proposed based on DOE (design of experiment ${ }^{[7]}$ and the BP (back propagation $)^{[8]}$ neural network. The selected process parameters that affect the feeding system are taken as the input variables, and the volume values of shrinkage cavities and porosities obtained from the simulation are taken as the output response. A mathematical model 
based on the BP neural network is established to build the relationship between the input variables and the output response. Then the nonlinear optimization function of the genetic algorithm is adopted to search for the extreme value. Thus the optimization of the feeding system is complete. This method reduces simulation times in the feeding system optimization process. Furthermore, the system of input variables is arbitrary. All the controllable factors can be added to obtain a global optimized solution.

\section{Optimal process based on BP neural network and genetic algorithm}

The optimal processes and steps based on the BP neural network and genetic algorithm are shown in Fig. 1.

(1) Process variables are selected to design the DOE test according to the forming mechanism of shrinkage porosities and cavities in casting solidification.

(2) Using finite-difference numerical analysis software to simulate sample points, the shrinkage porosity and shrinkage cavity volumes in the entire testing scheme are obtained.

(3) According to the numerical simulation results, the approximate alternative model for optimization is built using the BP neural network.

(4) The BP neural network and the BP neural network approximate model are optimized using a genetic algorithm for the optimization of the steel casting feeding system, and the global optimization value is obtained.

(5) According to the global optimization value obtained, a 3D solid model of the casting process is generated. Subsequently, numerical simulation is carried out to obtain the volume of porosity and shrinkage.

(6) If the error between the objective function value obtained through simulation and the desired objective function value is within the allowable range, the entire optimization process is stopped, and the obtained design variable is the optimal design value. Otherwise, the approximate optimal solution obtained by the recalculation, the objective function value obtained by simulation, and the constraint values are added to the sample data set, and the approximate alternative model is updated. Thus, the purpose of such iterative optimization is to find the optimal solution to meet the expected objective function.

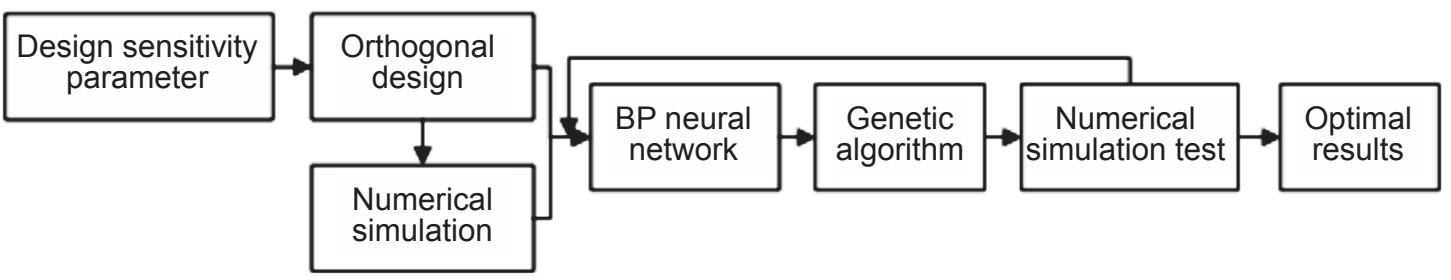

Fig. 1: Optimized combination strategy

\section{Design variables and objective function in optimization of feeding system}

\subsection{Design variable}

Taking into account the formation mechanism of shrinkage porosity and shrinkage cavity, factors such as pouring temperature, pouring speed, risers, pads, and chills have different effects on the volume of shrinkage porosity and cavity. The influence trend is shown in Table 1. These influencing factors do not act alone but interact with each other. Selection of process parameters in Table 1 to achieve simultaneous coagulation or sequential solidification requires engineering experience for the specific steel castings.

Throughout the design of a feeding system, the casting material generally will not be changed. Considering the controllability of the above factors in engineering practice, the type of riser, riser size, chiller and pouring temperature are selected as the sensitivity parameters for the feeding system optimization.

Table 1: Factors affecting the shrinkage porosity and cavity of steel castings

\begin{tabular}{|c|c|c|c|c|c|c|c|c|c|c|c|}
\hline \multirow{2}{*}{ Defect } & \multirow{2}{*}{$\begin{array}{c}\text { Shrinkage } \\
\text { rate }\end{array}$} & \multicolumn{2}{|c|}{ Top pouring } & \multicolumn{2}{|c|}{ Bottom pouring } & \multicolumn{3}{|c|}{ Riser } & \multirow{2}{*}{ Chill } & \multirow{2}{*}{ Pad } & \multirow{2}{*}{$\begin{array}{l}\text { Pressure } \\
\text { feeding }\end{array}$} \\
\hline & & Temp. & Speed & Temperature & Speed & Position & Type & Size & & & \\
\hline $\begin{array}{c}\text { Shrinkage } \\
\text { cavity }\end{array}$ & $\uparrow$ & $\downarrow$ & $\uparrow$ & $\uparrow$ & $\downarrow$ & $\leftrightarrow$ & & & $\leftrightarrow$ & & $\leftrightarrow$ \\
\hline $\begin{array}{c}\text { Shrinkage } \\
\text { porosity }\end{array}$ & $\uparrow$ & $\leftrightarrow$ & $\downarrow$ & $\leftrightarrow$ & $\uparrow$ & $\leftrightarrow$ & & & $\leftrightarrow$ & & $\downarrow$ \\
\hline
\end{tabular}

Note: $\uparrow$ means it increases with the rise of the factor; $\downarrow$ means it decreases with the rise of the factor; $\leftrightarrow$ means it is related to the specific steel castings. 


\subsection{Objective function}

Steel casting feeding system optimization is aimed at minimizing the volume of shrinkage porosity and cavity and it is a multi-objective optimization.

(1) The mathematical model for the multi-objective optimization

The multi-objective optimization of a feeding system is that each objective function $F(X)$ must be as small as possible while satisfying the constraints. It can be expressed as equation (1):

$\min _{X \in S} F(X)=F(X)=\left(f_{1}(X), f_{2}(X), f_{3}(X)\right)^{T}, \quad X=\left(x_{1}, x_{2}, x_{3}, x_{4}, x_{5}\right)^{T}$ subject to $g_{s}(X) \leqslant 0, s=1,2, \mathrm{~L}, p \quad h_{t}(X)=0, t=1,2, \mathrm{~L}, q$

where $F(X)$ is the objective function vector; $x_{1}, x_{2}, x_{3}, x_{4}$, $x_{5}$ are decision variables; $S$ is a constraint; the vector $X$ $=\left(x_{1}, x_{2}, \mathrm{~L}, x_{\mathrm{n}}\right)^{T}$ made of decision variables is called the decision vector; $g_{s}(X)$ and $h_{t}(X)$ indicate the inequality constraints, and determine the feasible range of decision variables.

(2) The solution for the multi-objective problem

Some contradictions exist between the component functions of the multi-objective optimization problem. $f_{v_{c}}(X)\left(v_{c}\right.$ represents the volume of shrinkage cavity), $f_{v_{p}}(X)$ ( $v_{p}$ represents the volume of shrinkage porosity), and $f_{v_{r}}(X)$ ( $v_{r}$ represents the volume of the riser) may be contradictory. So it is very difficult to find the unique solution to make all factors optimal at the same time. The objective weighting method proposed by Zadeh and Geoffrion ${ }^{[12]}$ is proposed to solve the multiobjective problem. The objective weighting method uses different weight coefficients to combine the several objective functions into a single objective function, and then uses this single objective function to solve the problem, as shown in equation (2):

$$
F(X)=\sum_{i=1}^{k} w_{i} f_{i}(X), X=\left(x_{1}, x_{2}, \mathrm{~L}, x_{n}\right)^{T}
$$

where weight coefficient $w_{i} \geqslant 0$. Meanwhile, the following equation, $\sum_{i=1}^{k} w_{i}=1$, should be added to ensure the commonality.

The multi-objective optimization uses the weighted score to measure the achievement of each optimization objective. The resolved procedure of the weighted score method are as follows:

(1) The weight of the index, which indicates the volume of shrinkage cavity, porosity and riser, should be determined. Based on the quality evaluation standard from engineering practice, the shrinkage cavity should not exist in the casting. However, a small amount of shrinkage porosity may be presented. Thus the smaller the volume of the risers, the higher the process yield. Hence, the weight index of the shrinkage cavity is the largest of the three factors. The weight of the shrinkage cavity volume is set at 0.4 , the shrinkage porosity volume weight is at 0.3 and the riser volume weight is also at 0.3 . The weights are not a constant value but can be adjusted according to specific problems.

(2) The calculation of the membership degree $y$ is as follows:

$$
y=\frac{\left(m_{\max }-m\right)}{\left(m_{\max }-m_{\min }\right)}
$$

where $m_{\max }$ indicates the maximum index, and $m_{\min }$ indicates the minimum index. Having a smaller volume of shrinkage cavities, shrinkage porosities, and the riser is better, so the membership degree of the minimum index is 1 .

(3) We calculate the comprehensive score $F$ for each sample:

$$
F=y_{k} \times 0.4+y_{s} \times 0.3+y_{r} \times 0.3
$$

where $y_{k}$ indicates the index membership of shrinkage cavities, $y_{s}$ indicates the index membership of shrinkage porosity, and $y_{r}$ indicates the index membership of the riser.

\section{Establishment and application of optimization model for feeding system}

\subsection{Design of experiments}

DOE (Design of Experiment) is a study of the interaction among factors to determine the superior level of key factors, so as to find the optimal level combination of technological parameters in a test. According to the characteristics of optimization of the steel casting feeding system, orthogonal design is chosen, which arranges and analyzes multi-factor by testing them scientifically using orthogonal table. Orthogonal design has fewer tests and uniform distribution of test samples in the same design space. The defined process of DOE method is shown in Fig. 2.

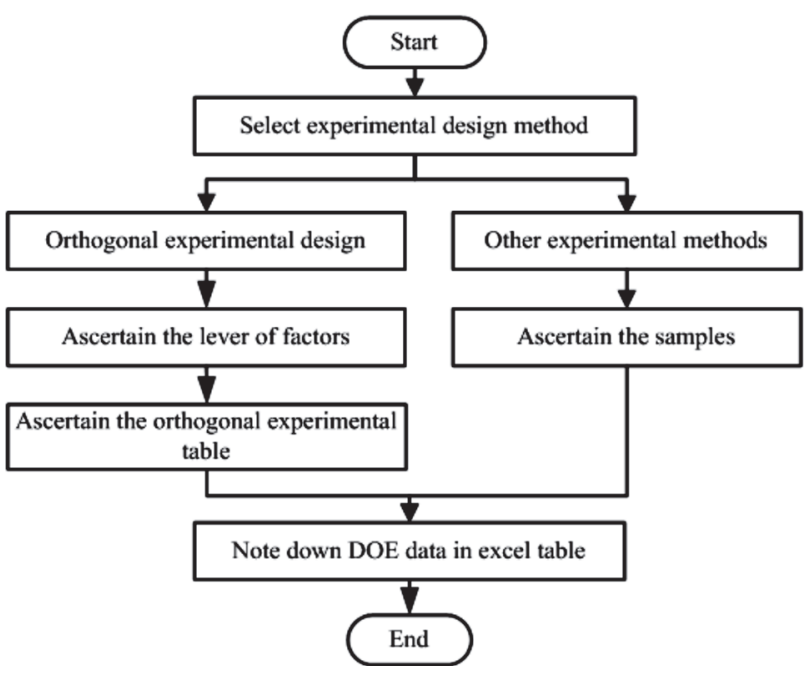

Fig. 2: DOE method defined process

\subsection{Approximate model based on BP neural network and Genetic Algorithm Optimization}

The BP neural network has a simple structure, many adjustable parameters, training algorithm and good maneuverability. The BP neural network is used to build an approximate model of the feeding system optimization. The network input is set as the process parameters and the network output is set as the volume of shrinkage cavity and porosity (optimized index). The BP neural network is established between the network 
input and output, and the experimental data of the feeding system optimization is studied. Then, the trained neural network is used as a mathematical model to map the nonlinear relationship between the sensitive process parameters and the optimized index. Figure 3 shows the neural network of a single hidden layer feed-forward. It is also known as the three-layer feed-forward network or three-layer perceptron, including the input layer, the hidden layer and the output layer.

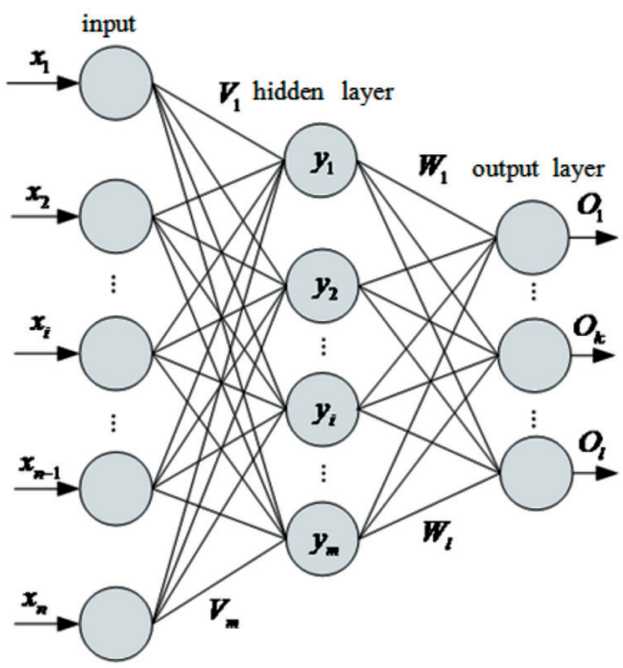

Fig. 3: Structure of BP neural network

The genetic algorithm is a search heuristic that mimics the process of natural selection. This heuristic is routinely used to generate useful solutions to optimization and search problems. Genetic algorithms belong to the larger class of evolutionary algorithms, which generate solutions to optimization problems using techniques inspired by natural evolution, such as inheritance, mutation, selection and crossover. Genetic algorithms need only the target value information rather than high order gradient information. Thus the limitations on the functions are very few. The functions can be either the explicit function such as the mathematical expression, mapping matrix, or the implicit function, such as neural networks. It has strong commonality and can be used for any optimizations of the large and highly nonlinear discrete multimodal functions.

According to the characteristics of the optimization function, a suitable BP neural network is built. Then the BP neural network is exercised by the input/output data of a nonlinear function. Then, the exercised data can be used to predict the function output. For the extreme optimization of the genetic algorithm, the predicted output is taken as an individual fitness value. Besides the global optimal value, the corresponding input values are derived by selection, crossover and mutation operators, as shown in Fig. 4.

\section{Experimental verification}

The travelling wheel, a kind of common steel casting, usually works under great contact stress and friction, so it needs better
Training fitting of neural network

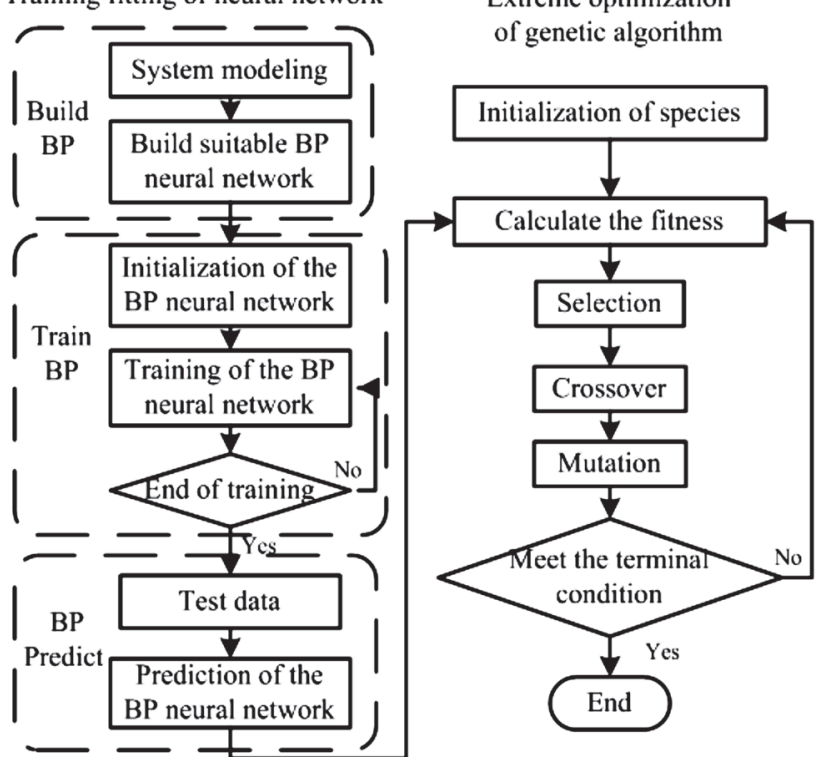

Fig. 4: A flow chart illustrating the genetic algorithm optimizing BP neural network

wear resistance and hardness. The material of the travelling wheel (Fig. 5) is ZG270-500. The casting process of the travelling wheel is analyzed, which is presented below. Three waist circular risers and three rectangular chills are placed on the hot spot in the circle structure for feeding; a cylindrical open riser is placed on the central boss. Considering the simple structure of the casting, bottom pouring is chosen for the gating system. According to the process analysis, the initial casting process design (Fig. 6) was obtained through process calculation using the modulus method.

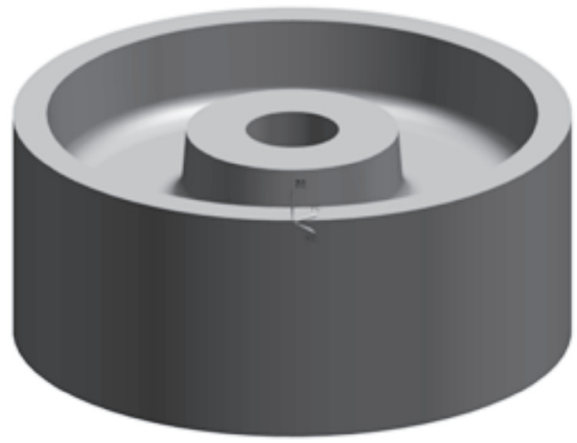

Fig. 5: Casting of a travelling wheel

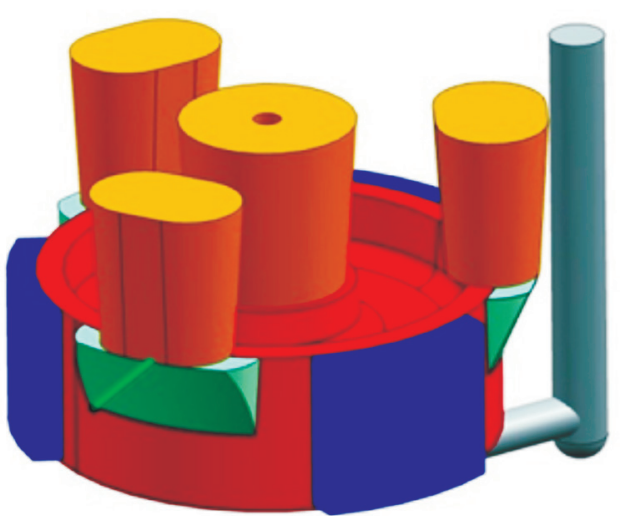

Fig. 6: Casting process of travelling wheel 
The results of numerical simulation are shown in Fig. 7. There is no shrinkage cavity and porosity in the casting, as shown in Fig. 7(a) and Fig. 7(b). The process yield of this process scheme is $52.35 \%$. Pouring test and cutting detection for this process were carried out in a factory. As shown in Fig. 8(a), the safe distance from the lower part of the funnel area in the side riser to the steel castings is $85 \mathrm{~mm}$. As well, the safe distance of the middle riser is $87 \mathrm{~mm}$ in Fig. 8(b). So the original process is too conservative and the process yield is very low. Therefore, it is necessary to optimize the process of the feeding system to reduce the riser volume and improve the process yield.

To analyze the travelling wheel in Fig. 5, five major process factors affecting the volume of shrinkage cavity and porosity are selected preliminarily. The five factors are A - riser type, B - riser cross-sectional area, C - riser height, D - chill, and E - pouring temperature. According to the experience of the design and process knowledge, four level values for each factor are determined within the range of given appropriate values. The five factors and four levels of value constitute the factor level table shown in Table 2. With the 5 factors (design variation) and 4 levels (design variation values) determined, the orthogonal experiment L16 $\left(4^{5}\right)$ has been generated automatically as shown in Table 3 .

The optimization function of traveling wheel optimization has 5 variables, so the length of individual which uses real number coding in genetic algorithm is 5. After three computational operations, there are three fitness curves shown in Figs. 9, 10 and 11. It is easy to conclude that the algorithm is convergent and the population fitness value is very stable after 60 computational operations, so the global best solution has been found. The optimal individuals obtained after three calculations of genetic algorithm operations are 0.951 , 0.972, 0.976, as shown in Table 4. Because the difference of

\section{Shrinkage}

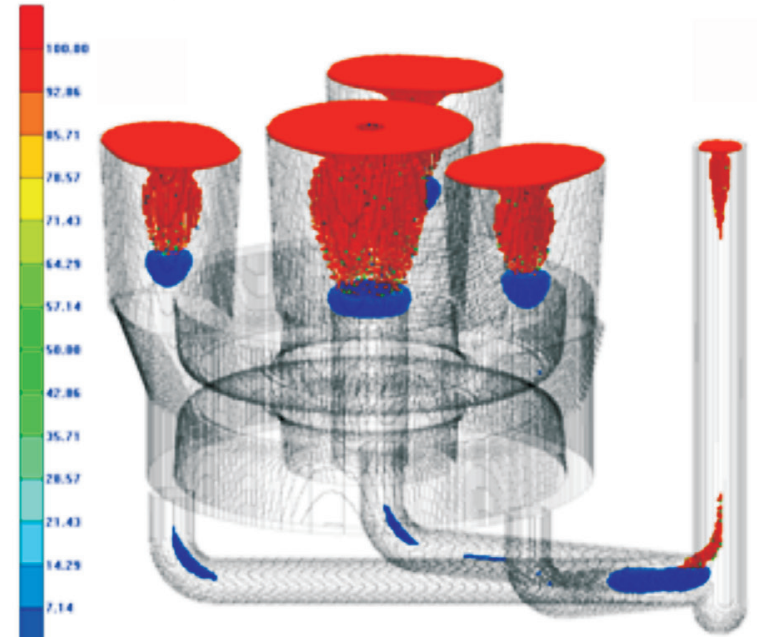

(a)

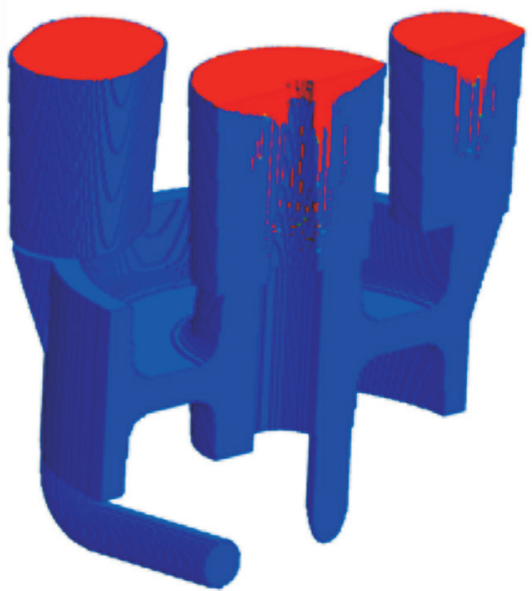

(b)

Fig. 7: Simulated temperature field of travelling wheel with initial process at 1,693.92 s showing the shrinkage (a) and the cutaway view (b)
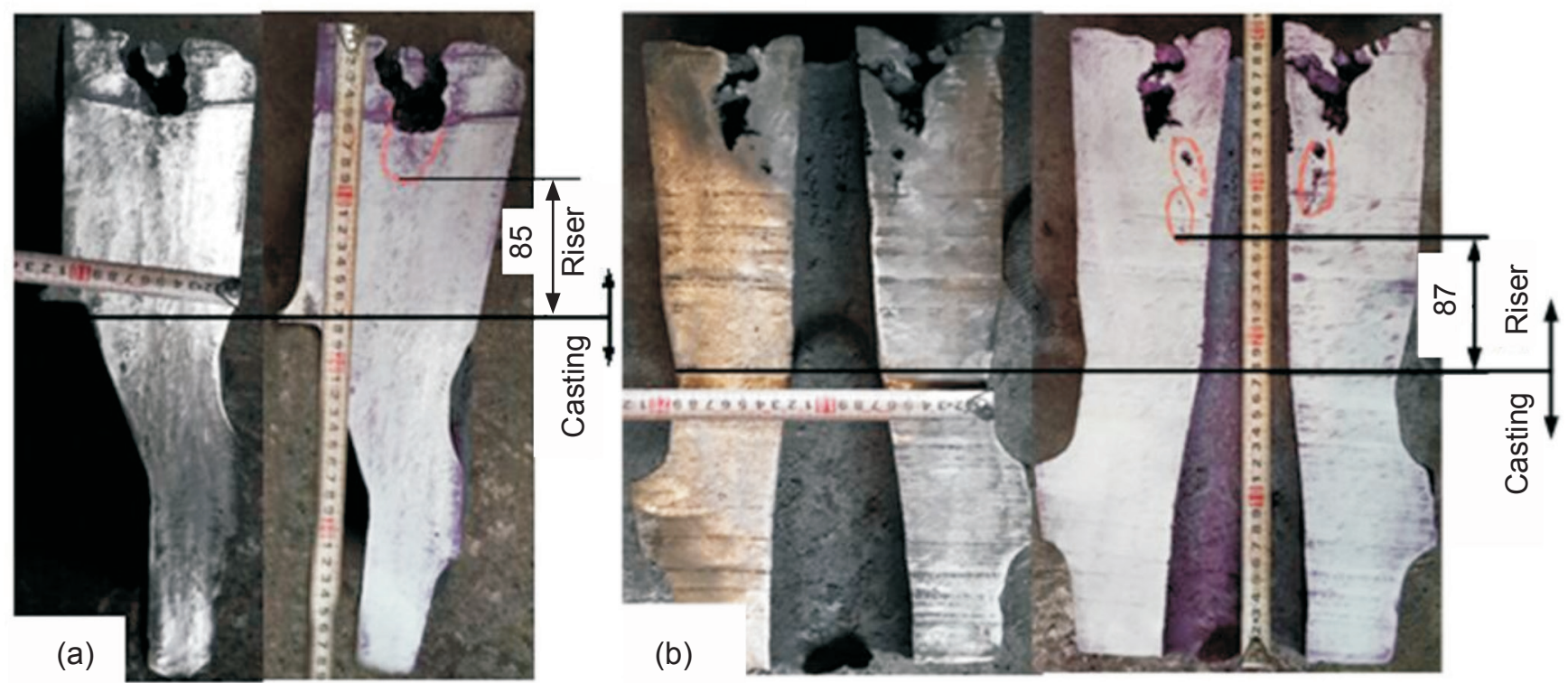

Fig. 8: Longitudinally cross section along the centerline of side riser (a) and middle riser (b) showing defect positions 
Table 2: Factors and levels of orthogonal test

\begin{tabular}{|c|c|c|c|c|}
\hline Factor & Level 1 & Level 2 & Level 3 & Level 4 \\
\hline A & Blind riser & Open riser & $\begin{array}{l}\text { Blind riser with insulating } \\
\text { sleeve }\end{array}$ & $\begin{array}{l}\text { Open riser with insulating } \\
\text { sleeve }\end{array}$ \\
\hline \multirow{3}{*}{ B } & $\mathrm{d}=170 \mathrm{~mm}$ & $\mathrm{~d}=195 \mathrm{~mm}$ & $\mathrm{~d}=210 \mathrm{~mm}$ & $\mathrm{~d}=225 \mathrm{~mm}$ \\
\hline & $a=100 \mathrm{~mm}$ & $a=110 \mathrm{~mm}$ & $a=120 \mathrm{~mm}$ & $a=130 \mathrm{~mm}$ \\
\hline & $b=1.5 a$ & $b=1.5 a$ & $b=1.5 a$ & $b=1.5 a$ \\
\hline \multirow{2}{*}{ C } & $h=0.7 d$ & $h=0.8 d$ & $h=0.9 d$ & $h=1.0 d$ \\
\hline & $\mathrm{h}=1.2 \mathrm{a}$ & $h=1.4 a$ & $h=1.6 a$ & $h=1.65 a$ \\
\hline $\mathrm{D}$ & - & $200 \times 200 \times 20(\mathrm{~mm})$ & $200 \times 200 \times 30(\mathrm{~mm})$ & $200 \times 200 \times 40(\mathrm{~mm})$ \\
\hline$E$ & $1,550^{\circ} \mathrm{C}$ & $1,570^{\circ} \mathrm{C}$ & $1,590^{\circ} \mathrm{C}$ & $1,610^{\circ} \mathrm{C}$ \\
\hline
\end{tabular}

Note: A - riser type; B - cross-section size of riser; C - riser height; D - chill; E - pouring temperature.

Table 3: Orthogonal experiment L16 $\left(4^{5}\right)$

\begin{tabular}{|c|c|c|c|c|c|}
\hline NO. & $\mathbf{A}$ & B & C & D & E \\
\hline 1 & Blind riser & $\begin{array}{c}d=170 \mathrm{~mm} \\
a=100 \mathrm{~mm}, b=1.5 a\end{array}$ & $\begin{array}{l}h=0.7 d \\
h=1.2 a\end{array}$ & - & $1,550^{\circ} \mathrm{C}$ \\
\hline 2 & Blind riser & $\begin{array}{c}d=195 \mathrm{~mm} \\
a=110 \mathrm{~mm}, \mathrm{~b}=1.5 a\end{array}$ & $\begin{array}{l}h=0.8 d \\
h=1.4 a\end{array}$ & $200 \times 200 \times 20(\mathrm{~mm})$ & $1,570^{\circ} \mathrm{C}$ \\
\hline 3 & Blind riser & $\begin{array}{c}d=210 \mathrm{~mm} \\
a=120 \mathrm{~mm}, b=1.5 a\end{array}$ & $\begin{array}{l}h=0.9 d \\
h=1.6 a\end{array}$ & $200 \times 200 \times 30(\mathrm{~mm})$ & $1,590^{\circ} \mathrm{C}$ \\
\hline 4 & Blind riser & $\begin{array}{c}d=225 \mathrm{~mm} \\
a=130 \mathrm{~mm}, b=1.5 a\end{array}$ & $\begin{array}{l}h=1.0 d \\
h=1.65 a\end{array}$ & $200 \times 200 \times 40(\mathrm{~mm})$ & $1,610^{\circ} \mathrm{C}$ \\
\hline 5 & Open riser & $\begin{array}{c}d=170 \mathrm{~mm} \\
a=100 \mathrm{~mm}, b=1.5 a\end{array}$ & $\begin{array}{l}h=0.8 d \\
h=1.4 a\end{array}$ & $200 \times 200 \times 30(\mathrm{~mm})$ & $1,610^{\circ} \mathrm{C}$ \\
\hline 6 & Open riser & $\begin{array}{c}d=195 \mathrm{~mm} \\
a=110 \mathrm{~mm}, b=1.5 a\end{array}$ & $\begin{array}{l}h=0.7 d \\
h=1.2 a\end{array}$ & $200 \times 200 \times 40(\mathrm{~mm})$ & $1,590^{\circ} \mathrm{C}$ \\
\hline 7 & Open riser & $\begin{array}{c}d=210 \mathrm{~mm} \\
a=120 \mathrm{~mm}, b=1.5 a\end{array}$ & $\begin{array}{l}h=1.0 d \\
h=1.65 a\end{array}$ & - & $1,570^{\circ} \mathrm{C}$ \\
\hline 8 & Open riser & $\begin{array}{c}d=225 \mathrm{~mm} \\
a=130 \mathrm{~mm}, b=1.5 a\end{array}$ & $\begin{array}{l}h=0.9 d \\
h=1.6 a\end{array}$ & $200 \times 200 \times 20(\mathrm{~mm})$ & $1,550^{\circ} \mathrm{C}$ \\
\hline 9 & $\begin{array}{l}\text { Blind riser with } \\
\text { insulating sleeve }\end{array}$ & $\begin{array}{c}d=170 \mathrm{~mm} \\
a=100 \mathrm{~mm}, b=1.5 a\end{array}$ & $\begin{array}{l}h=0.9 d \\
h=1.6 a\end{array}$ & $200 \times 200 \times 40(\mathrm{~mm})$ & $1,570^{\circ} \mathrm{C}$ \\
\hline 10 & $\begin{array}{l}\text { Blind riser with } \\
\text { insulating sleeve }\end{array}$ & $\begin{array}{c}d=195 \mathrm{~mm} \\
a=110 \mathrm{~mm}, b=1.5 a\end{array}$ & $\begin{array}{l}h=1.0 d \\
h=1.65 a\end{array}$ & $200 \times 200 \times 30(\mathrm{~mm})$ & $1,550^{\circ} \mathrm{C}$ \\
\hline 11 & $\begin{array}{l}\text { Blind riser with } \\
\text { insulating sleeve }\end{array}$ & $\begin{array}{c}d=210 \mathrm{~mm} \\
a=120 \mathrm{~mm}, b=1.5 a\end{array}$ & $\begin{array}{l}h=0.7 d \\
h=1.2 a\end{array}$ & $200 \times 200 \times 20(\mathrm{~mm})$ & $1,610^{\circ} \mathrm{C}$ \\
\hline 12 & $\begin{array}{l}\text { Blind riser with } \\
\text { insulating sleeve }\end{array}$ & $\begin{array}{c}d=225 \mathrm{~mm} \\
a=130 \mathrm{~mm}, b=1.5 a\end{array}$ & $\begin{array}{l}h=0.8 d \\
h=1.4 a\end{array}$ & - & $1,590^{\circ} \mathrm{C}$ \\
\hline 13 & $\begin{array}{l}\text { Open riser with } \\
\text { insulating sleeve }\end{array}$ & $\begin{array}{c}d=170 \mathrm{~mm} \\
a=100 \mathrm{~mm}, b=1.5 a\end{array}$ & $\begin{array}{l}h=1.0 d \\
h=1.65 a\end{array}$ & $200 \times 200 \times 20(\mathrm{~mm})$ & $1,590^{\circ} \mathrm{C}$ \\
\hline 14 & $\begin{array}{l}\text { Open riser with } \\
\text { insulating sleeve }\end{array}$ & $\begin{array}{c}\mathrm{d}=195 \mathrm{~mm} \\
\mathrm{a}=110 \mathrm{~mm}, \mathrm{~b}=1.5 a\end{array}$ & $\begin{array}{l}h=0.9 d \\
h=1.6 a\end{array}$ & - & $1,610^{\circ} \mathrm{C}$ \\
\hline 15 & $\begin{array}{l}\text { Open riser with } \\
\text { insulating sleeve }\end{array}$ & $\begin{array}{c}d=210 \mathrm{~mm} \\
a=120 \mathrm{~mm}, \mathrm{~b}=1.5 a\end{array}$ & $\begin{array}{l}h=0.8 d \\
h=1.4 a\end{array}$ & $200 \times 200 \times 40(\mathrm{~mm})$ & $1,550^{\circ} \mathrm{C}$ \\
\hline 16 & $\begin{array}{c}\text { Open riser with } \\
\text { insulating sleeve }\end{array}$ & $\begin{array}{c}d=225 \mathrm{~mm} \\
a=130 \mathrm{~mm}, b=1.5 a\end{array}$ & $\begin{array}{l}h=0.7 d \\
h=1.2 a\end{array}$ & $200 \times 200 \times 30(\mathrm{~mm})$ & $1,570^{\circ} \mathrm{C}$ \\
\hline
\end{tabular}

parameters in three optimal schemes is very small, the third scheme has been chosen and the optimization parameters are converted to corresponding casting process parameters as shown in Table 5.

To verify the reliability of the optimization of the feeding system for steel castings, the pouring experiment has been 


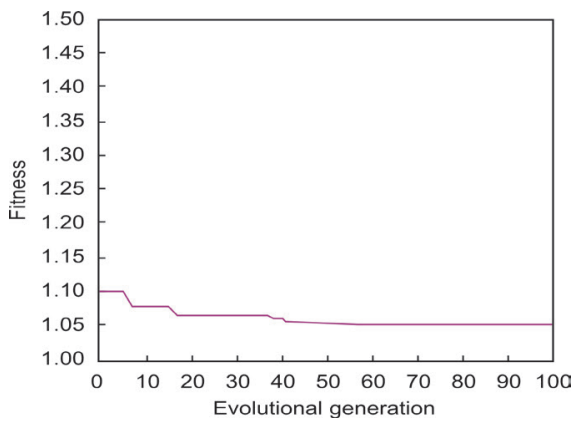

Fig. 9: Fitness curve of 1st calculation

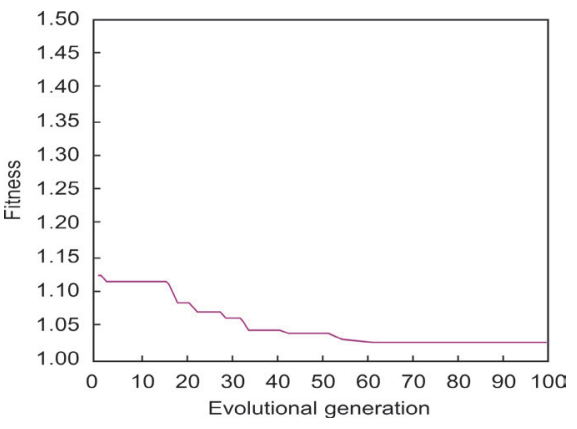

Fig. 10: Fitness curve of 2 nd calculation

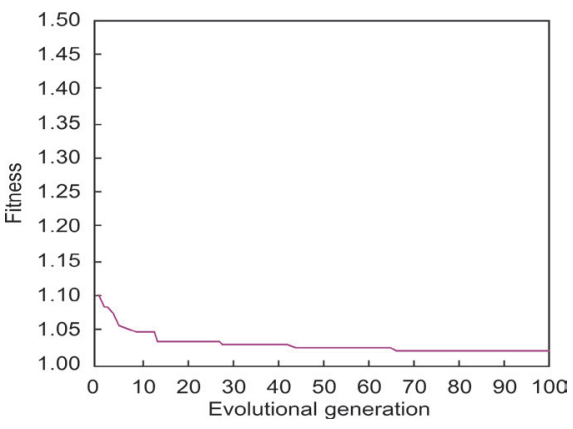

Fig. 11: Fitness curve of 3 rd calculation

Table 4: Optimal value and optimal parameters after three calculations

$\begin{array}{ccccccc}\text { Compute times } & \text { Optimal value } & \text { A } & \text { B } & \text { C } & \text { D } & 3,740 \\ 1 & 0.951 & 4 & 72,090 & 7,565 & 3,740 \\ 2 & 0.972 & 4 & 73,360 & 7,567 & 3,780\end{array}$

Table 5: Optimization of process parameters

$\begin{array}{ccccc}\text { Compute times } & \text { Riser types } & \text { Cross section of riser } & \text { Riser height } & \text { Chill } \\ 3 & \begin{array}{c}\text { Open riser with } \\ \text { insulation sleeve }\end{array} & \begin{array}{c}\mathrm{d}=200 \mathrm{~mm} \\ \mathrm{a}=106 \mathrm{~mm}, \mathrm{~b}=1.5 \mathrm{a}\end{array} & \mathrm{h}=180 \mathrm{~mm} & 200 \times 200 \times 31.5(\mathrm{~mm})\end{array}$

conducted. A three-dimensional model of the optimized process is shown in Fig. 12. Furan resin self-setting sand is used as the mould material. All the surfaces of the mould that will contact the molten metal are coated to prevent leakage and burning-on, in order to obtain a good surface quality. Figure 13 shows the moulding for the travelling wheel and Fig. 14 shows the flask of the travelling wheel.

The time of pouring takes about 30 seconds. When molten steel rises to $150-250 \mathrm{~mm}$ of the riser height during pouring, an insulating cover should be added. The casting has been separated from sand and the moulding box as soon as it is has cooled. Then, the middle riser and the side riser are cut from the casting using an oxyacetylene flame. To make it easy to observe the distribution of the porosity and shrinkage, the risers are separated from the middle using wire-electrode

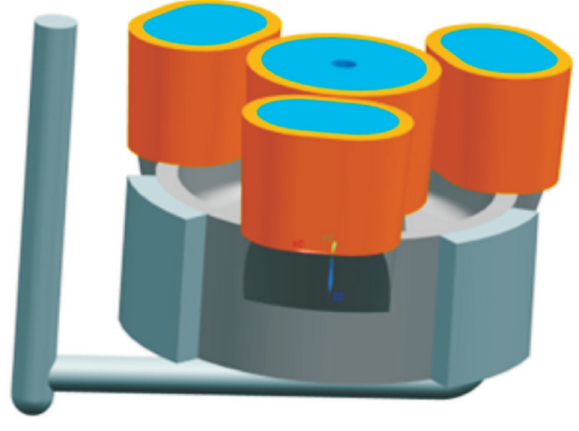

Fig. 12: Optimized process

cutting. Both penetrant testing (PT) and ultrasonic testing (UT) are used to detect the defects in the profile surface and to detect the internal quality of casting.
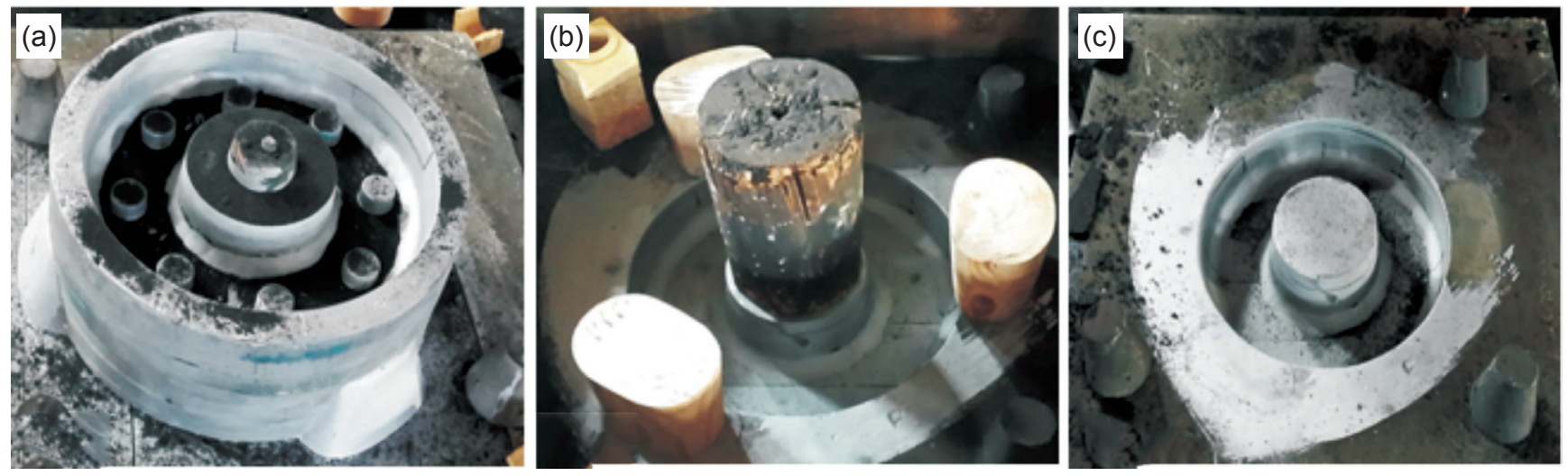

Fig. 13: Wooden moulds for travelling wheel: (a) bottom mould, (b) riser, (c) upper mould 

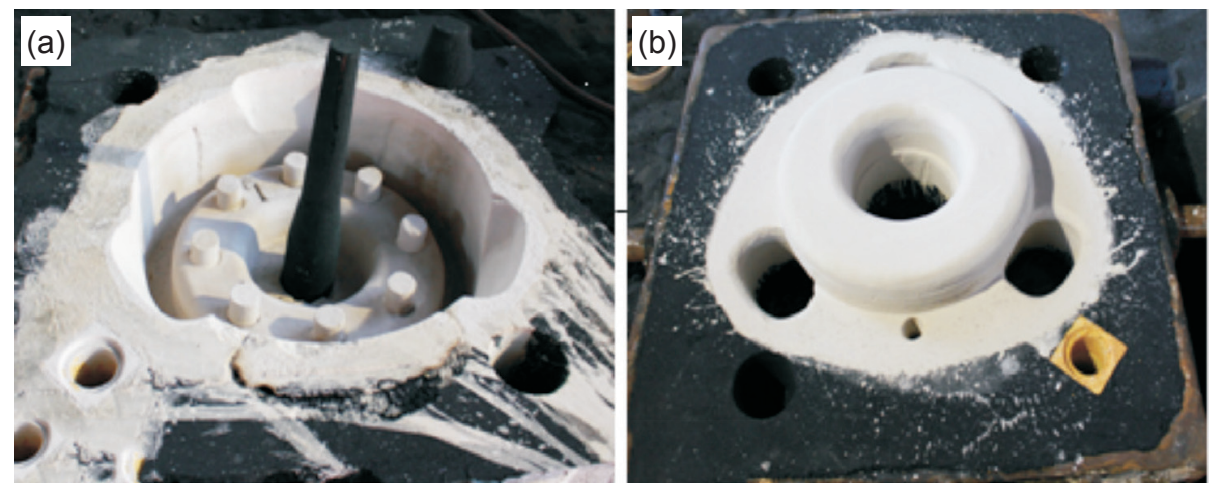

Fig. 14: Flask of cast steel travelling wheel: (a) drag, (b) cope

The comparison between the results of PT \& UT and the simulated results in the optimization scheme are shown in Fig. 15. Figure 15(a) shows that no defect has existed in the casting under the middle riser. Figure 15(c) shows the result of PT \& UT of the side riser, showing no shrinkage or porosity in the casting. Further, the safe distance between the lower part of the shrinkage cavity and the upper plane of the casting is $50 \mathrm{~mm}$. It can be concluded that the size of the risers in the travelling wheel optimized process is enough to feed the casting.
Figure 15(b) shows the simulated dissection result of the quantitative shrinkage cavity and the shrinkage porosity of the optimization scheme. It can be found that there is no defect in the casting under both the side riser and the middle riser. In addition, the riser volume is $5.48 \times 10^{6} \mathrm{~mm}^{3}$ smaller than the original scheme. Thus, this scheme is better and reveals the effectiveness of the BP neural network model optimized by the genetic algorithm in process optimization of the travelling wheel.

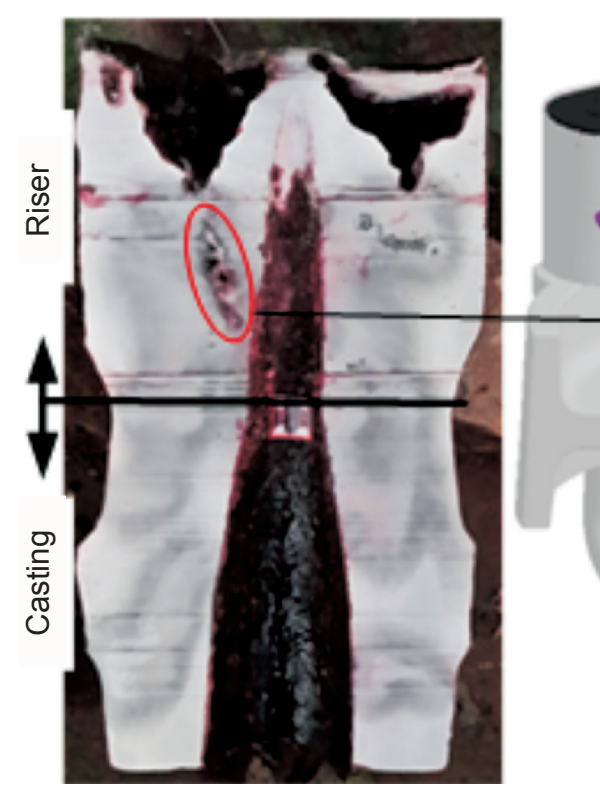

(a) (b)

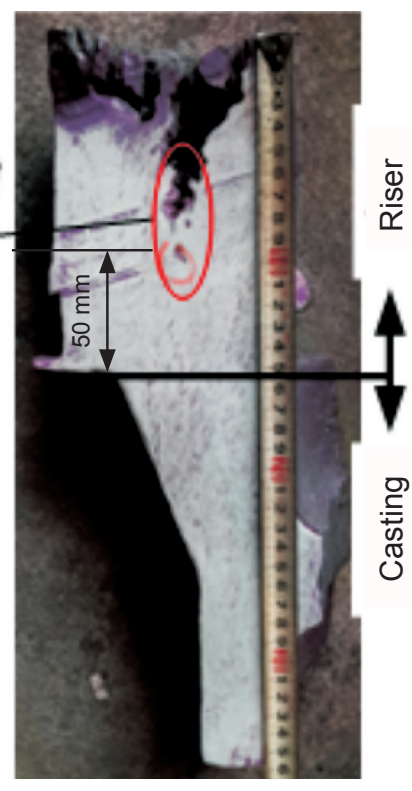

(c)

Fig. 15: Flaw detection results (PT \& UT) of optimized scheme: lognitudinal cross section along the centerline of middle riser (a) and side riser (c); simulated results (b)

\section{Conclusion}

It is difficult to obtain a quantitative mathematical model in optimization of feeding system for steel castings, because there are many process parameters affecting the final shrinkage and porosity in the process of steel production. Sensitive process parameters are selected from many factors affecting the feeding system for steel castings, and they are sampled by orthogonal experiment design to build the design variable space. In this study, the process optimization model of the feeding system of steel castings based on the BP neural network and the optimum route using genetic algorithm are established. By modeling the typical cast-steel travelling wheel with the BP neural network and optimizing it with the genetic algorithm, the optimized process scheme is obtained and pouring experimental verification is conducted. The experimental results show that compared to the initial process, the process yield with the optimized riser increases by $4.1 \%$, 
the volume of the risers decreases by $5.48 \times 10^{6} \mathrm{~mm}^{3}$, and there are no shrinkage cavity or porosity defects inside the casting. Therefore, the effectiveness and practicality of the combinatorial optimization strategy are verified.

\section{References}

[1] China Foundry Association. 2013 China foundry industry statistical data officially released. Foundry Technology, 2014 (6): 11. (In Chinese)

[2] Foundry Institution of Chinese Mechanical Engineering Society. Casting Manual. Beijing: China Machine Press, 2011. (In Chinese)

[3] Liang Chen. Quality-Efficient-Green Foundry Industry Development - Interview of China Foundry Association of Vice Chairman Huang Tianyou. Aviation Manufacturing Technology, 2011, (z1): 68-70. (In Chinese)

[4] Liu Baicheng. The trend of development of casting technology and computer simulation. Foundry Technology, 2005 (7): 611617. (In Chinese)

[5] Ransing R S and Sood M P. Optimization in castings-An overview of relevant computational technologies and future challenges. Metallurgical and Materials Transactions B, 2006, 37(6): 905-911.
[6] Gao Shangshu and Yu Zhiya. Three equation method to calculate the riser. Foundry, 2000 (9): 533-537. (In Chinese)

[7] Pan Feng. Research on the model of combination approximation and its application in lightweight design of car body. Ph.D. Thesis. Shanghai: Shanghai Jiao Tong University, 2011. (In Chinese)

[8] Buscema M. Back propagation neural networks. Substance Use \& Misuse, 1998, 33(2): 233-270.

[9] Li Chenxi. Casting Process Design and Casting Defects Control. Beijing: Chemical Industry Press, 2009. (In Chinese)

[10] Li Zhifeng. Mechanical optimization design. Beijing: Higher Education Press, 2011: 267. (In Chinese)

[11] Niyama E, Uchida T, Morikawa M, et al. A method of shrinkage prediction and its application to steel casting practice. International Journal of Cast Metals Research, 1982, 7(3): 5263.

[12] Marler R T and Arora J S. Survey of multi-objective optimization methods for engineering. Structural and Multidisciplinary Optimization, 2004, 26(6): 369-395.

[13] Yang De. Experimental Design and Analysis (The first edition). Beijing: China Agriculture Press, 2002: 508. (In Chinese)

[14] Wang Xiaoping and Cao Liming. Genetic Algorithm: Theory, Application and Software Realization. Xi'an: Xi'an Jiao Tong University Press, 2002. (In Chinese)

This research is financially supported by the Program for New Century Excellent Talents in University (Nos. NCET-13-0229, NCET-09-0396), the National Science \& Technology Key Projects of Numerical Control (Nos. 2012ZX04010-031, 2012ZX0412011) and the National High Technology Research and Development Program ("863" Program) of China (No. 2013031003). 